\title{
Validated Ultraviolet-Spectrometric Method for Determination of Sofosbuvir in Tablets Formulation
}

\author{
Mohamed A. El Hamd ${ }^{1 *}$, Ramadan Ali ${ }^{1}$, Adel A. Marzouk ${ }^{2}$, Osama H. Abdelmageed ${ }^{3}$ \\ ${ }^{1}$ Department of Pharmaceutical Analytical Chemistry, Faculty of Pharmacy, Al Azhar University, Assiut, Egypt. \\ ${ }^{2}$ Department of Pharmaceutical Chemistry, Faculty of Pharmacy, Al Azhar University, Assiut, Egypt. \\ ${ }^{3}$ Department of Pharmaceutical and Phytochemistry, Faculty of Pharmacy, King Abdulaziz University, Jeddah 21589, Kingdom of Saudi Arabia.
}

\begin{tabular}{|c|c|}
\hline ARTICLE INFO & ABSTRACT \\
\hline Article history: & \multirow{9}{*}{$\begin{array}{l}\text { A simple, direct and rapid ultraviolet spectrometric method was developed and validated for determination of } \\
\text { sofosbuvir (SOF) in its tablets formulation. SOF was dissolved in methanol and measured in ultraviolet region at } \\
\lambda_{\max } \text { of } 260 \mathrm{~nm} \text {. The linearity of the calibration curve was over the concentration range of } 5-100 \mu \mathrm{g} / \mathrm{mL} \text { with a } \\
\text { correlation coefficient of } 0.999 \text {. The sensitivity was checked as the limit of detection and limit of quantification } \\
\text { which were found to be } 1.6 \text { and } 4.8 \mu \mathrm{g} / \mathrm{mL} \text { respectively. The percentage recoveries of SOF, after extraction from } \\
\text { its tablets, were ranged from } 98.23 \pm 1.04 \%-99.38 \pm 0.40 \% \text { with a relative standard division less than } 2.0 \% \\
\text { indicating acceptable accuracy and precision of the developed method. Further studies of the accuracy and } \\
\text { precision of the proposed method were performed using standard addition method; the mean quantitative } \\
\text { recovery of such studies were found to be in the range } 97.99 \pm 0.32 \text { to } 99.69 \pm 0.15 \text { with RSD } \leq 2.0 \% \text {. These } \\
\text { levels of accuracy and precision obtained indicate suitability of the developed method for the quality control } \\
\text { analysis of the SOF in its tablets formulation. }\end{array}$} \\
\hline Received on: 13/09/2016 & \\
\hline Accepted on: 07/11/2016 & \\
\hline Available online: $27 / 02 / 2017$ & \\
\hline Key words: & \\
\hline Sofosbuvir, tablets & \\
\hline formulation, Quality control & \\
\hline analysis, UV & \\
\hline Spectrophotometry. & \\
\hline
\end{tabular}

\section{INTRODUCTION}

Sofosbuvir, an isopropyl (2S)-2-[[] $(2 \mathrm{R}, 3 \mathrm{R}, 4 \mathrm{R}, 5 \mathrm{R})-5$ (2,4-dioxopyrimidin-1-yl) -4-fluoro-3- hydroxy-4-methyltetrahydrofuran-2-yl] methoxy-phenoxy-phosphoryl]amino] propanoate (SOF, Fig. 1) is a recent novel nucleotide derivative was described as a typical inhibitor of hepatitis $\mathrm{C}$ virus (HCV) (Summers et al., 2014) in Egypt. The discovery of this drug was considered as a promising new one for treatment of patients suffer from HCV. It is prodrug of 2'-deoxy-2'-fluoro-2'-Cmethyluridine monophosphate that is phosphorylated intracellularly to the active triphosphate form, which acts as an inhibitor of $\mathrm{HCV}$ non-structural 5B ribonucleic acid polymerase (Imran et al., 2013). Chronic infection with HCV leads to liver cirrhosis, which in turn results in development of life-threatening complications, such as

\footnotetext{
* Corresponding Author

Mohamed A. El Hamd, Department of Pharmaceutical Analytical Chemistry, Faculty of Pharmacy, Al Azhar University, Assiut, Egypt. Email: aboelhamdmohamed@gmail.com
}

hepatocellular carcinoma (Pan et al., 2016). Before the discovery of SOF the treatment of HCV was achieved by interferon (Rong and Perelson, 2010) which are poorly tolerated by patients with cirrhosis and cause high rates of severe and serious adverse events, leading many patients to discontinue treatment with interferonbased regimens (Bourlière Marc et al., 2012, Hézode Christophe et al., 2013). Recently, SOF in combination with other medicinal products had been used for the treatment of chronic $\mathrm{HCV}$ in adults (European Medicines Agency., 2013). Now SOF is available in tablets formulation with a content uniformity so important to be checked because the treatment with SOF is based mainly in its presence in an appropriate quantity in the body (Sovaldi, 2016). To the best of our knowledge, no reported analytical or pharmacopoeia methods are available for determination of SOF in its tablets formulation. So far the reported methods available for the determination of SOF were used for bioequivalence studies of SOF in rat (Pan, Chen, 2016; Shi et al., 2015) and human (Rezk Mamdouh et al., 2016, Rezk Mamdouh et al., 2015) plasma using ultra-performance liquid chromatography tandem mass spectrometry. 
Therefore the objective of this work is to develop, for the first time, a new validated UV spectrometric method for simple, rapid and accurate determination of SOF its tablets formulation.

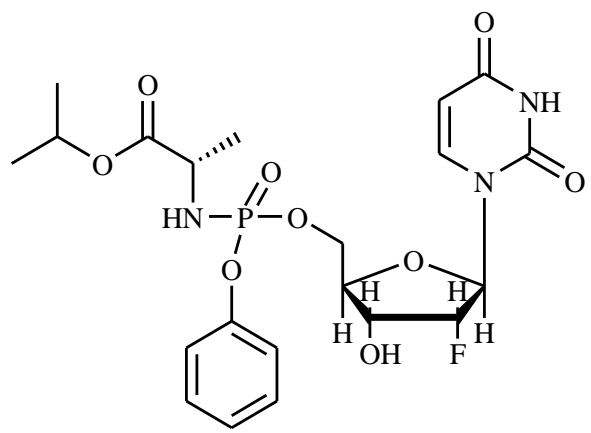

Fig. 1: Chemical structure of SOF.

\section{EXPERIMENTAL}

\section{Materials and methods}

Reference standard of SOF was kindly offered as a gift from Pharmaceutical Supervisory Board (Cairo, Egypt, batch NO. SF0320615). A simulated tablets of SOF were made as reported (sofosbuvir. Tablets); where the tablet core was made form mannitol, cellulose, colloidal anhydrous silica, magnesium stearate, and a tablet film-coating was made from polyvinyl alcohol, macrogol, talc, and iron oxide. Pharmaceutical tablets are commercially available in local market under the name of Sovaldi $^{\mathrm{TM}}$ tablets were claimed to contain $400 \mathrm{mg} \mathrm{SOF} /$ tablet (Gilead Science, Inc. CA 94404 USA, batch NO. 619890461). All solvents and chemicals such as acetic anhydride, acetone, acetonitrile, amyl alcohol, benzene, carbon tetra-chloride, dichloroethane, dichloromethane, dimethyl formamide, dimethyl sulphoxide, 1,4-dioxane, ethanol, ethyl acetate, hexane, isopropanol, methanol, triethylamine, hydrochloric acid $(\mathrm{HCl})$, sodium hydroxide $(\mathrm{NaOH})$, cellulose, anhydrous silica, magnesium stearate, polyvinyl alcohol, macrogol, talc, and iron oxide were of analytical grade and were obtained from El-Nasr Chemical Co., (Cairo, Egypt).

Absorbance measurements were made on double beam UV/visible spectrophotometers model 1601 (Shimadzu, Tokyo, Japan) with pairs of one-cm thickness matched quartz cells. Additionally, digital analytical balance (AG 29, Mettler Toledo, Glattbrugg, Switzerland) and MLW type thermostatically controlled water bath (Memmert GmbH, Schwabach, Germany) were also used throughout this work.

\section{Preparation of reference solution}

The reference stock solution of SOF $(1 \mathrm{mg} / \mathrm{mL})$ was prepared by dissolved an appropriate amount of its powder in methanol and stored for one week in the refrigerator at $4^{\circ} \mathrm{C}$ without significant changes. The working solutions were prepared by an appropriate dilution of the stock solution with distilled water to cover the concentration range of the calibration curve $(5-100$ $\mu \mathrm{g} / \mathrm{mL}$ ) and to prepare the quality control samples (QCs) at 5, 40 and $100 \mu \mathrm{g} / \mathrm{mL}$.

\section{Preparation of tablets (Sovaldi ${ }^{\mathrm{TM}}$ ) sample solution}

Twenty tablets of Sovaldi ${ }^{\mathrm{TM}}$ were weighed and finely powdered; a quantity of the powder equivalent to $100 \mathrm{mg}$ of active ingredient was weighed and transferred into a beaker, treated with about $20 \mathrm{~mL}$ of chloroform. The contents of the beaker were swirled, sonicated for about $5 \mathrm{~min}$, and then filtered into round bottom flask through a Whatmann No. 42 filter paper. The residue was further washed with about $5 \times 3 \mathrm{~mL}$ of chloroform. The combined filtrate and washing were evaporated to dryness. The residue left was dissolved in appropriate volume of methanol and the resultant solution was further transferred to $100-\mathrm{mL}$ calibrated volumetric flask and then completed to volume with the same solvent to give $1 \mathrm{mg} / \mathrm{mL}$ of tablet sample stock solution.

\section{General procedure}

Different aliquots of the reference standard or sample solution were transferred into $10-\mathrm{mL}$ calibrated volumetric flasks and after completed to the volume with distilled water, to obtain a final concentration of a concentration range of $5-100 \mu \mathrm{g} / \mathrm{mL}$, the absorbance of the resulting solutions was measured at $\lambda_{\max }$ of 260 $\mathrm{nm}$ against a blank experiment treated similarly.

\section{RESULTS AND DISCUSSION}

\section{Spectrophotometric standardization}

To select the most appropriate diluting solvent; a working solutions at the QC concentration levels were diluted with acetic anhydride, acetone, acetonitrile, amyl alcohol, benzene, carbon tetra-chloride, dichloroethane, dichloromethane, dimethyl formamide, dimethyl sulphoxide, 1,4-dioxane, ethanol, ethyl acetate, hexane, isopropanol, methanol, triethylamine, water, $1 \mathrm{~N}$ $\mathrm{HCl}$ and $1 \mathrm{~N} \mathrm{NaOH}$ (Table 1).

Table 1: Effect of diluting solvents on SOF $(40 \mu \mathrm{g} / \mathrm{mL}) \mathrm{UV}$ - absorbance.

\begin{tabular}{clc} 
Number & Solvent $^{1}$ & Absorbance $\pm \mathbf{S D}, \mathbf{n}=\mathbf{3}$ \\
\hline 1 & Acetic anhydride & $-*$ \\
2 & Acetone & $0.498 \pm 0.006$ \\
3 & Acetonitrile & $0.567 \pm 0.007$ \\
4 & Amyl alcohol & $0.575 \pm 0.000$ \\
5 & Benzene & $0.030 \pm 0.018$ \\
6 & Carbon tetra chloride & $-*$ \\
7 & Dichloroethane & $0.560 \pm 0.013$ \\
8 & Dichloromethane & $0.588 \pm 0.014$ \\
9 & Dimethyl formamide & $-*$ \\
10 & Dimethyl sulphoxide & $0.457 \pm 0.002$ \\
11 & Dioxane & $0.531 \pm 0.012$ \\
12 & Ethanol & $0.623 \pm 0.006$ \\
13 & Ethyl acetate & $0.071 \pm 0.017$ \\
14 & Hexane & $0.517 \pm 0.010$ \\
15 & isopropanol & $0.561 \pm 0.001$ \\
16 & Methanol & $0.633 \pm 0.044$ \\
17 & Triethylamine & $-*$ \\
18 & Water & $0.652 \pm 0.024$ \\
19 & 1N HCl & $0.619 \pm 0.005$ \\
20 & 1N NaOH & $0.558 \pm 0.007$
\end{tabular}

${ }^{1}$ No relation between the dielectric constants for these solvents and the obtained data was found; * - = No absorbance detected 


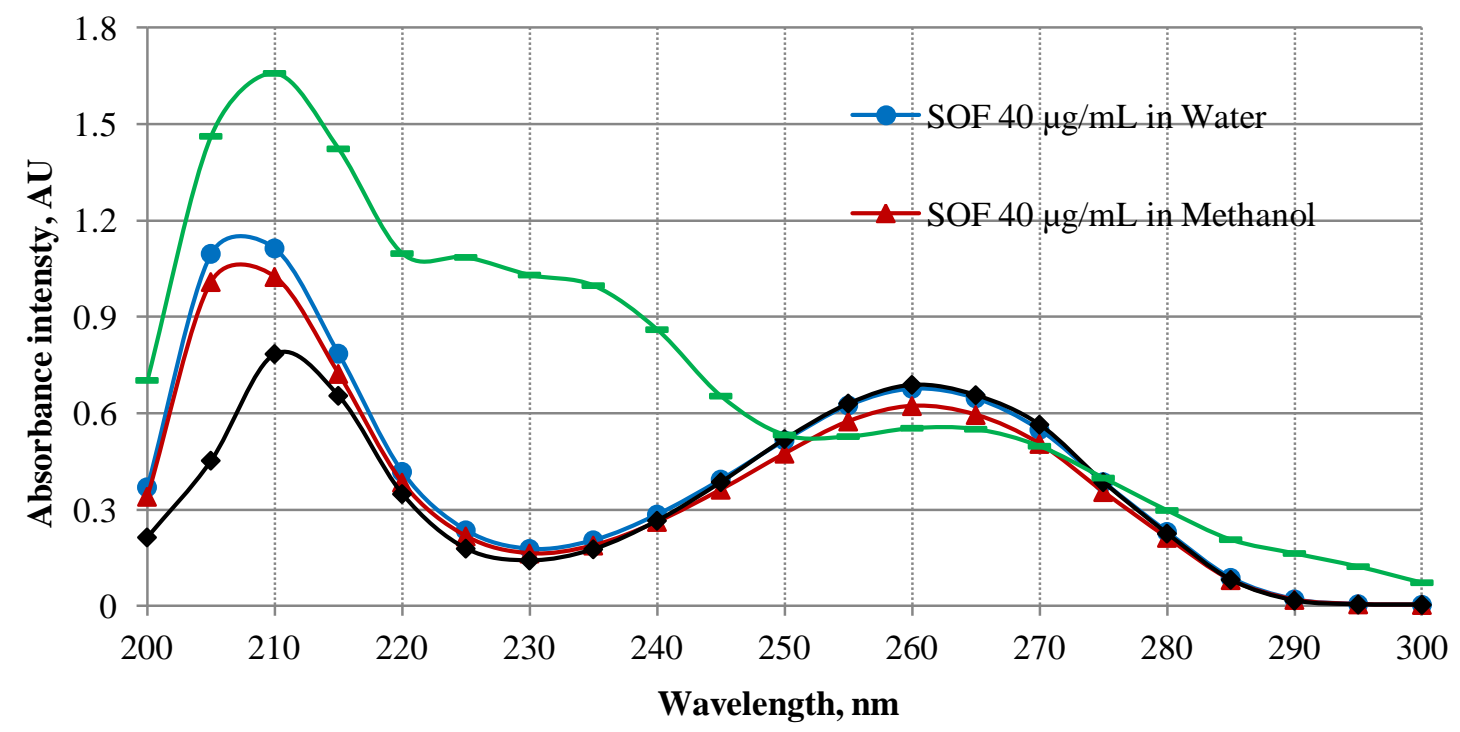

Fig. 2: UV-spectra of reference SOF after dilution with water, methanol, $1 \mathrm{~N}$ of $\mathrm{HCl}$ or $1 \mathrm{~N} \mathrm{NaOH}$ at $40 \mu \mathrm{g} / \mathrm{mL}$.

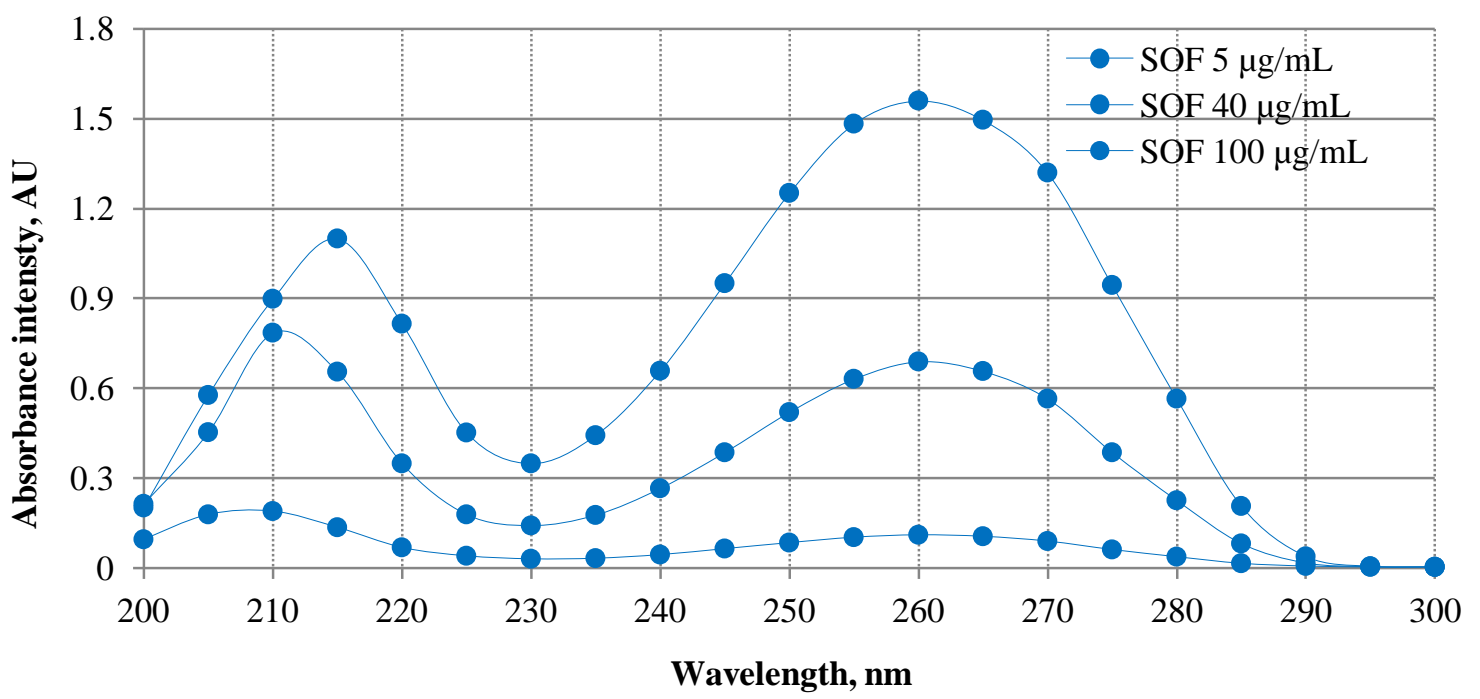

Fig. 3: UV-spectra of reference SOF at different concentration levels of the QC samples $(5,40,100 \mu \mathrm{g} / \mathrm{mL})$ after dilution with distilled water.

For all the absorbance of the resulting solutions was measured at $\lambda_{\max }$ of $260 \mathrm{~nm}$ against blank experiments treated similarly. The data showed in Table 1 was revealed that the maximum absorption and constant smooth peaks were observed with some of the selected organic solvents such as ethanol and methanol as well as water and $1 \mathrm{~N} \mathrm{HCl}$. The absorbance intensity was decreased significantly with acetone, acetonitrile, amyl alcohol, benzene, dichloroethane, dichloromethane, dimethyl formamide, dimethyl sulphoxide, 1,4-dioxane, ethyl acetate, hexane, isopropanol and $1 \mathrm{~N} \mathrm{NaOH}$. On the other hand by dilution with acetic anhydride, carbon tetra-chloride, and triethylamine no absorbance was detected for SOF. Therefore, water as a plentiful and green solvent was selected as diluting solvent before the spectrometric measurements for the next experiments, Fig. 2 and
Fig. 3. The measurements was directly achieved after dilution at room temperature $\left(25 \pm 5^{\circ} \mathrm{C}\right)$ and the absorbance values of the resulted solution remained stable for more than one hour after dilution with distilled water.

\section{Assay performance \\ Calibration curves and sensitivity}

The calibration curve was linear over the concentration range of $5-100 \mu \mathrm{g} / \mathrm{mL}$ of SOF simulated tablets, Fig.4. The linearity were assessed by preparing and analyzing of seven concentration points of SOF after extracted from these at 5, 10, 20, $40,60,80$, and $100 \mu \mathrm{g} / \mathrm{mL}$, triplicate measurements for each concentration were performed. The regression equations obtained by least squared was $\mathrm{Y}=0.0157 \mathrm{X}+0.039$, where $\mathrm{Y}$ represents the 
absorbance intensity response and $\mathrm{X}$ is the analyte concentration, $\mu \mathrm{g} / \mathrm{mL}$. The limit of detection (LOD) and limit of quantification (LOQ) were calculated according to the following equations of LOD $=3.3 \mathrm{~S}_{\mathrm{a}} / \mathrm{b}$ and LOQ $=10 \mathrm{~S}_{\mathrm{a}} / \mathrm{b}$ where $\mathrm{S}_{\mathrm{a}}$ is the standard deviation of the blank and $b$ is the slope of the regression line. LOD and LOQ were found to be 1.6 and $4.8 \mu \mathrm{g} / \mathrm{mL}$, respectively. Molar absorptivity $(\varepsilon, \mathrm{L} / \mathrm{mol} \times \mathrm{cm})$ was determined within the entire linearity range. Moreover the Sandell's sensitivity (Ss) is calculated by using the formula of $\mathrm{Ss}=\varepsilon \times \mathrm{X}, \mu \mathrm{g} / \mathrm{mL}$. Further quantitative parameters of such analysis are summarized in Table 2.

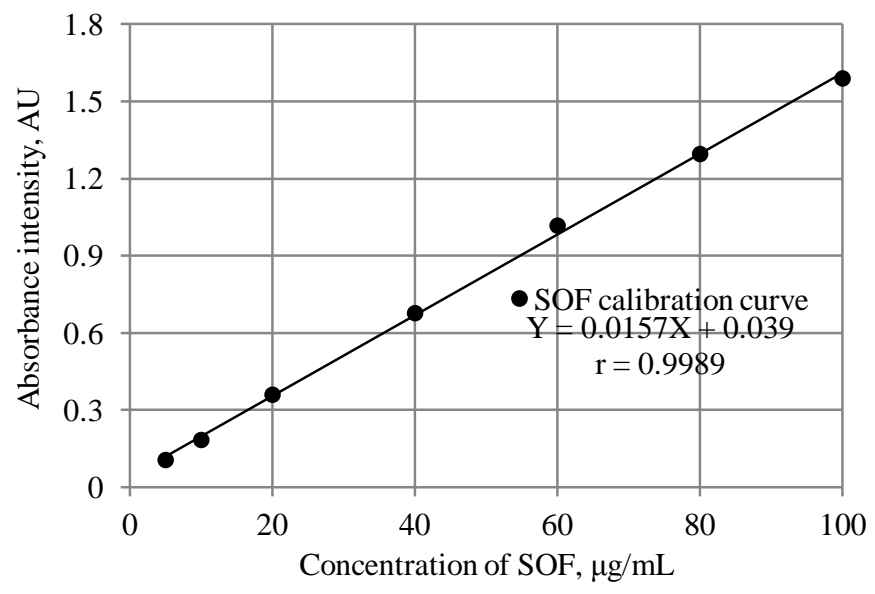

Fig 4 Calibration curve of SOF after extracted from the simulated tablets.

Table 2: Quantitative parameters for the analysis of SOF by the proposed method

\begin{tabular}{lc}
\hline \multicolumn{1}{c}{ Parameters } & Values \\
\hline Working wavelength, $\lambda_{\max } \mathrm{nm}$ & 260 \\
Beer-Lamberts law range, $\mu \mathrm{g} / \mathrm{mL}$ & $5-100$ \\
Linear regression equation, $\mathrm{Y}^{1}$ & $0.0157 \mathrm{X}^{2}+0.039$ \\
Correlation coefficient, $r$ & 0.9989 \\
$\mathrm{LOD}, \mu \mathrm{g} / \mathrm{mL}$ & 1.6 \\
$\mathrm{LOQ}, \mu \mathrm{g} / \mathrm{mL}$ & 4.8 \\
$\mathrm{Molar}^{1}$ absorptivity ${ }^{3} \varepsilon, \mathrm{mL} / \mathrm{mmol} \times \mathrm{cm}$ & 188.87 \\
$\mathrm{~A}^{1 \%}{ }_{1 \mathrm{~cm}}{ }^{1}$ & 167.85 \\
Sandal's sensitivity $^{5}\left(\mu \mathrm{g} / \mathrm{cm}^{-2} / 0.001\right.$ absorption units $)$ & 0.0116 \\
${ }^{1} \mathrm{Y}:$ the absorbance intensity; ${ }^{2} \mathrm{X}:$ the sample concentration, $\mu \mathrm{g} / \mathrm{mL} ;{ }^{3} \varepsilon=\left(\mathrm{Y}_{2^{-}}\right.$ \\
$\left.\mathrm{Y}_{1} / \mathrm{X}_{2}-\mathrm{X}_{1}\right) /$ cuvette thickness, $1 \mathrm{~cm} ;{ }^{4} \mathrm{~A}^{1 \%}{ }_{1 \mathrm{~cm}}=\varepsilon \times 10 / \mathrm{Mw} ;{ }^{5} \mathrm{Ss}=\varepsilon \times \mathrm{X}, \mu \mathrm{g} / \mathrm{mL}$.
\end{tabular}

\section{Validation of the developed method}

The method was validated in compliance with ICH guidelines (2005). The following parameters were investigated for the validation of the developed method:

\section{Precision and accuracy}

The precision and accuracy of the proposed method were evaluated for intra- and inter-day variability. Five standard solution replicates at three different concentrations levels of the QC reference samples $(5,40$, and $100 \mu \mathrm{g} / \mathrm{mL})$ within same day and over five consecutive days were studied. The precision was expressed as a percentage of relative standard deviation (RSD\%) while the accuracy expressed as the relative error (RE\%). The
RSD $\%$ values were $\leq 1.80 \%$ and $\leq 2.0 \%$ for intra-day and interdays. The RE\% was observed within 0.66 and $2.0 \%$ for intra- and inter-days respectively. These results indicate that the present method was accurate, reliable and has repeatability for the quantitative analysis of SOF in tablets, Table 3.

Table 3: Precision and accuracy data of SOF reference solution analysed by the proposed method.

\begin{tabular}{ccccccc}
\hline \multirow{2}{*}{$\begin{array}{c}\text { SOF, } \\
\boldsymbol{\mu g} / \mathbf{m L}\end{array}$} & \multicolumn{3}{c}{ Intra-day $(\mathbf{n}=\mathbf{5})$} & \multicolumn{4}{c}{ Inter-day $(\mathbf{n}=5)$} \\
\hline 5 & $\begin{array}{c}\text { Found, } \boldsymbol{\mu g} / \mathbf{m L} \\
(\mathbf{m e a n} \pm \mathbf{S D})\end{array}$ & $\mathbf{R S D} \%$ & $\mathbf{R E \%}$ & $\begin{array}{c}\text { Found, } \boldsymbol{\mu g} / \mathbf{m L} \\
(\mathbf{m e a n} \pm \mathbf{S D})\end{array}$ & RSD\% & $\mathbf{R E \%}$ \\
40 & $4.97 \pm 0.09$ & 1.80 & 0.60 & $4.98 \pm 0.10$ & 2.00 & 0.40 \\
100 & $99.21 \pm 0.19$ & 0.48 & 1.98 & $39.32 \pm 0.41$ & 1.04 & 1.70 \\
\hline
\end{tabular}

The recovery studies were performed using standard addition method for further study of the accuracy and precision of the proposed method. This study was performed by adding known amounts of standard solution of SOF as a percent (50, 100, and $150 \%$ to the known concentration) to two concentration levels of the QC samples (5 and $40 \mu \mathrm{g} / \mathrm{mL}$ ). Each sample was subsequently analyzed for the total SOF content and the mean analytical recovery was expressed as the ratio between SOF concentrations found of the added amount to the nominated concentrations, expressed as recovery $\%$. The mean quantitative recovery of such studieswere found to be in the range $97.99 \pm 0.32$ to $99.69 \pm 0.15$ with RSD $\leq 2.0 \%$. These levels of accuracy and precisionobtained indicate suitability of the developed method for the quality control analysis of the SOF in its tabletsformulation, Table 4.

Table 4: Analysis of SOF tablets formulation and recovery\% study by standard addition method.

\begin{tabular}{|c|c|c|c|c|c|c|c|}
\hline \multirow[b]{2}{*}{ 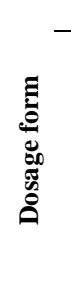 } & \multicolumn{7}{|c|}{ Standard addition method $(n=5)$} \\
\hline & 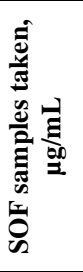 & 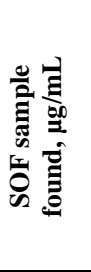 & 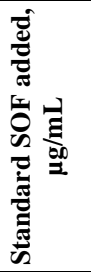 & 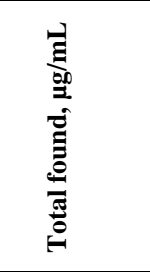 & 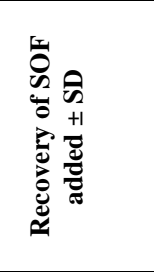 & है & $\begin{array}{l}\text { se } \\
\text { ax }\end{array}$ \\
\hline \multirow{6}{*}{ 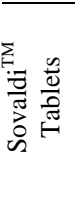 } & 5.0 & 4.97 & 2.5 & $7.32 \pm 0.21$ & $97.99 \pm 0.32$ & 0.33 & 2.00 \\
\hline & 5.0 & 4.97 & 5.0 & $9.82 \pm 0.10$ & $98.50 \pm 0.11$ & 0.11 & 1.50 \\
\hline & 5.0 & 4.97 & 7.5 & $12.31 \pm 0.25$ & $98.71 \pm 0.20$ & 0.20 & 1.30 \\
\hline & 40.0 & 39.98 & 20.0 & $59.80 \pm 0.21$ & $99.69 \pm 0.15$ & 0.15 & 0.30 \\
\hline & 40.0 & 39.98 & 40.0 & $78.90 \pm 0.12$ & $98.65 \pm 0.14$ & 0.14 & 1.35 \\
\hline & 40.0 & 39.98 & 60.0 & $99.52 \pm 0.21$ & $99.54 \pm 0.31$ & 0.31 & 0.46 \\
\hline
\end{tabular}

Analysis of simulated tablets preparation and content uniformity

A simulated SOF tablet sample was prepared and then analyzed for its SOF content at three different concentrations levels of the QC samples after extraction with chloroform. The recovery \% was calculated by comparing the absorbance of extracted samples to that of the pure analyte at the same concentration, Table 5. In addition the content uniformity of 10 tablets were also calculated (2009), Table 6. In both cases satisfactory results were obtained, where both precision and accuracy data obtained were within the limits allowed by $\mathrm{ICH}$ guidelines. 
Table 5: The recoveries of SOF after extraction from simulated tablets preparation.

\begin{tabular}{|c|c|c|c|c|}
\hline \multirow[t]{2}{*}{ Drug } & \multirow{2}{*}{$\begin{array}{c}\text { Nominal conc., } \\
\mu \mathrm{g} / \mathrm{mL}\end{array}$} & \multicolumn{3}{|c|}{ Recovery $\%, n=5$} \\
\hline & & Mean \pm SD & RSD \% & RE\% \\
\hline \multirow[t]{3}{*}{ SOF } & 5 & $98.32 \pm 1.04$ & 1.06 & 1.68 \\
\hline & 40 & $99.05 \pm 0.15$ & 0.15 & 0.95 \\
\hline & 100 & $99.38 \pm 0.40$ & 0.40 & 0.62 \\
\hline
\end{tabular}

Table 6: Content uniformity of SOF tablets formulation by the proposed method.

\begin{tabular}{cc}
\hline Number of observations & Found $\% \pm \mathbf{S D}, \mathbf{n}=\mathbf{3}$ \\
\hline 1 & $98.90 \pm 0.24$ \\
2 & $99.37 \pm 0.19$ \\
3 & $97.62 \pm 0.15$ \\
4 & $98.21 \pm 0.18$ \\
5 & $99.80 \pm 0.36$ \\
6 & $95.70 \pm 0.62$ \\
7 & $96.71 \pm 0.11$ \\
8 & $97.05 \pm 0.81$ \\
9 & $98.70 \pm 0.52$ \\
10 & $99.71 \pm 0.41$ \\
Mean \pm SD & $98.18 \pm 0.36$ \\
RSD $\%$ & 0.37 \\
RE\% & 1.82 \\
\hline
\end{tabular}

\section{Interferences and matrix effect}

In order to evaluate the matrix effect (ME) from other tablets excipient on the determination of the SOF, simulated blank tablets were extracted and spiked with the concentration levels QC samples $(5,40$, and $100 \mu \mathrm{g} / \mathrm{mL})$. These samples were determined together with pure standard containing no matrix components. ME was calculated as absorbance intensities ratio in the presence of matrix (A) divided by the mean of the absorbance in the absence of matrix (B). Potential interference by additives and excipients present in tablets formulation was eliminated by chloroform extraction prior to analysis. The mean recoveries of spiked SOF from its blank tablet were ranged from $99.10 \pm 0.01$ to $99.05 \pm$ 0.07 and were similar for all analyte concentrations at the level of QC samples without significant concentration dependence, Table 7. The RSD $\%$ was lower than $2 \%$, in all cases studied, indicating no significant matrix effect after chloroform extraction.

Table 7: The recoveries of SOF spiked to simulated blank tablets after extraction with chloroform.

\begin{tabular}{ccccc}
\hline \multirow{2}{*}{ Drug } & $\begin{array}{c}\text { Nominal conc., } \\
\boldsymbol{\mu g} / \mathbf{m L}\end{array}$ & \multicolumn{3}{c}{ Recovery\%, $\mathbf{n}=\mathbf{5}$} \\
\cline { 3 - 5 } & 5 & $99.20 \pm 0.12$ & 0.12 & 0.80 \\
\multirow{3}{*}{ SOF } & 40 & $99.05 \pm 0.07$ & 0.07 & 0.95 \\
& 100 & $99.10 \pm 0.01$ & 0.01 & 0.90 \\
\hline
\end{tabular}

\section{Degradation and selectivity study}

From chemical point of view the cited drug is considered as phosphate and ester derivative. Therefore, theoretically the hydrolysis these groups can be considered the best and easier way to prepare degraded sample. Hydrolysis of esters is usually catalysed by either acid or base in elevated temperature. Thus the reaction was carried out in presence of $1 \mathrm{~N} \mathrm{HCl}$ or $1 \mathrm{~N} \mathrm{NaOH}$. The results obtained after studying the degradation of authentic sample of the studied drug placed in a preheated thermostatically water bath at $90^{\circ} \mathrm{C}$ at different time interval $(10,20,30,40,50$ and 60 min). The data were summarized in Fig.5.

Fortunately, the UVspectra at $260 \mathrm{~nm}$ revealed that no significantly decrease in absorption spectra was observed in either $1 \mathrm{~N} \mathrm{HCl}$ nor $1 \mathrm{~N} \mathrm{NaOH}$ after heating for 1 hour at $90^{\circ} \mathrm{C}$ in a thermostatically water bath, indicated the suitability of the proposed method for determination of the cited drug even at the drastic condition and whatever the possibility of the presence of the degraded.

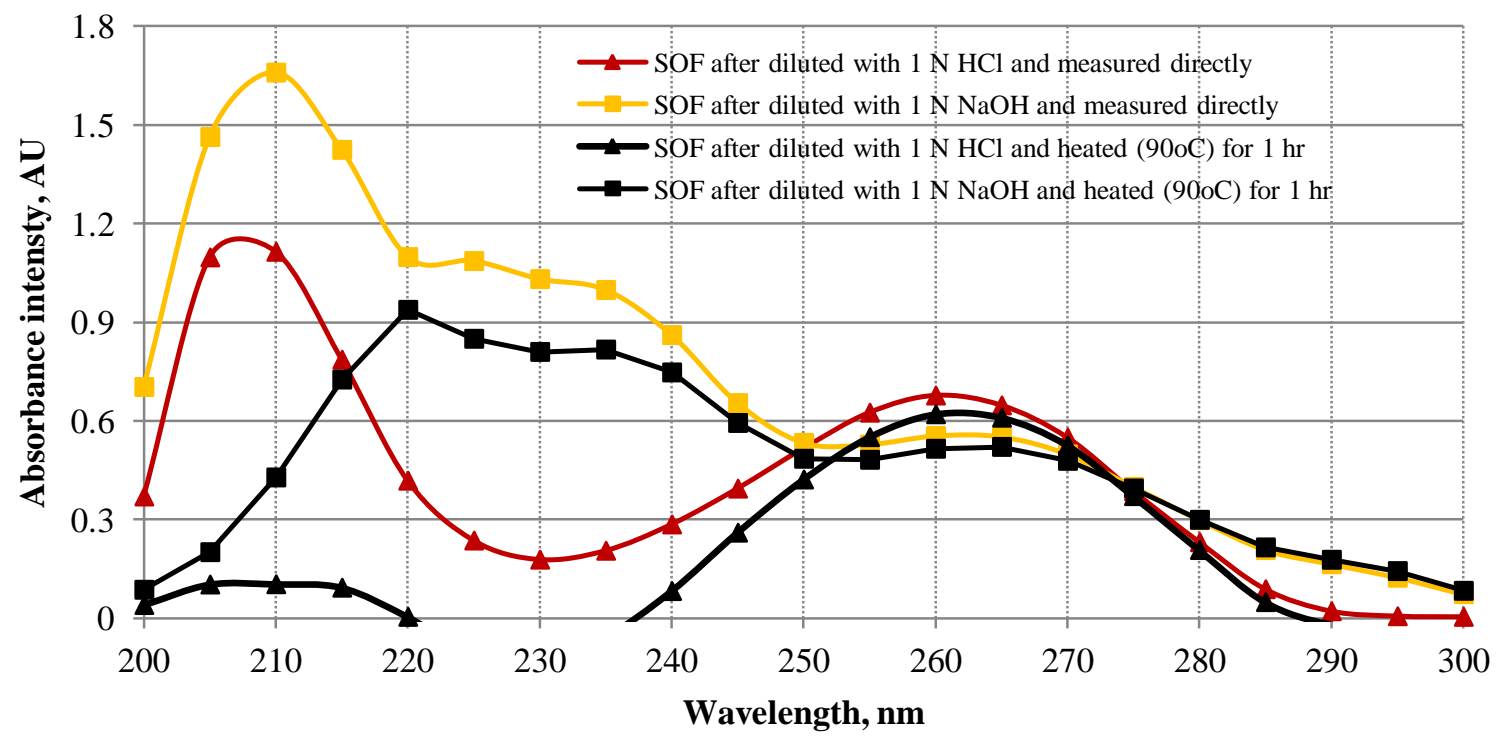

Fig. 5: UV-spectra of SOF $(40 \mu \mathrm{g} / \mathrm{mL})$ after dilution either with $1 \mathrm{~N} \mathrm{HCl}$ or $1 \mathrm{~N} \mathrm{NaOH}$ and measured directly or after heating for one hour in a water path preheated at $90{ }^{\circ} \mathrm{C}$. 
The ICH and USP guidelines recommend the evaluation of robustness of the proposed method during the development phase by testing the method parameters susceptibility to changes. This study was done by changing the parameter (s) under study while the other parameter (s) remained constant. In our case the involved parameter studied was room temperature $\left(25 \pm 5^{\circ} \mathrm{C}\right)$. The observed results compared to control experiments for the studied drug proved that there are no significance differences between the control (s) and those experiments carried out after variation of the room temperature over the range specified. Thus the results of such study proved the capacity of the proposed method to remain unaffected by small and deliberate variations in ambient temperature.

\section{CONCLUSION}

A new, simple and rapid UV-spectrometric method for determination sofosbuvir has been developed and validated. The developed method has cost-effective and shorter total running time as a first method for determination of SOF in its tablets formulation. The method was found to be precise, accurate and the results obtained are within the recommended limits allowed by ICH guidelines. Whatever, the present method could be successfully applied to the analysis of SOF in its tablets formulation for routine and quality-control analysis.

\section{Financial support and sponsorship: Nil.}

Conflict of Interests: There are no conflicts of interest.

\section{REFERENCES}

Validation of Analytical Procedures: Text and Methodology Q2 (R1). in ICH Harmonised Tripartite Guideline. 2005. London2009.

The British Pharmacopoeia, Majesty's stationary Office.

Bourlière Marc., Khaloun Asma., Wartelle-Bladou Claire., Oules Valérie., Portal Isabelle., Benali Souad., et al. Future treatment of patients with HCV cirrhosis. Liver International. 2012;32:113-9.

European Medicines Agency. International non-proprietary name: sofosbuvir. 2013.

Hézode Christophe., Fontaine Hélène., Dorival Céline., Larrey Dominique., Zoulim Fabien., Canva Valérie., et al. Triple therapy in treatment-experienced patients with HCV-cirrhosis in a multicentre cohort of the French Early Access Programme (ANRS CO20-CUPIC)NCT01514890. Journal of Hepatology. 2013;59:434-41.
Imran M, Manzoor S, Khattak NM, Khalid M, Ahmed QL, Parvaiz $\mathrm{F}$, et al. Current and future therapies for hepatitis $\mathrm{C}$ virus infection: from viral proteins to host targets. Archives of Virology. 2013;159:831-46

Pan C, Chen Y, Chen W, Zhou G, Jin L, Zheng Y, et al. Simultaneous determination of ledipasvir, sofosbuvir and its metabolite in rat plasma by UPLC-MS/MS and its application to a pharmacokinetic study. Journal of Chromatography B: Analytical Technologies in the Biomedical and Life Sciences. 2016;1:255-9.

Rezk Mamdouh R, Basalious Emad B, Amin Mohammed E. Novel and sensitive UPLC-MS/MS method for quantification of sofosbuvir in human plasma: application to a bioequivalence study. Biomedical chromatography. 2016:in press.

Rezk Mamdouh R, Basalious Emad B, Karim Iman A. Development of a sensitive UPLC-ESI-MS/MS method for quantification of sofosbuvir and its metabolite, GS-331007, in human plasma: Application to a bioequivalence study. Journal of Pharmaceutical and Biomedical Analysis. 2015;114:97-104.

Rong L, Perelson AS. Treatment of hepatitis C virus infection with interferon and small molecule direct antivirals: viral kinetics and modeling. Critical Reviews in Immunology. 2010;30:131-48.

Shi X, Zhu D, Lou J, Zhu B, Hu AR, Gan D. Evaluation of a rapid method for the simultaneous quantification of ribavirin, sofosbuvir and its metabolite in rat plasma by UPLC-MS/MS. Journal of Chromatography B: Analytical Technologies in the Biomedical and Life Sciences. 2015;1:353-7.

sofosbuvir. Tablets. Through the internet; https://www.medicines.org.uk/emc/medicine/28539.

Sovaldi. A cure for Hepatitis C - or just good business? Through the internet. 2016

Summers BB, Beavers JW, Klibanov OM. Sofosbuvir, a novel nucleotide analogue inhibitor used for the treatment of hepatitis $C$ virus. Journal of Pharmacy and Pharmacology. 2014;66:1653-66.

\section{How to cite this article:}

El-Hamd MA, Ali R, Marzouk AA, Abdelmageed OH. Validated Ultraviolet-Spectrometric Method for Determination of Sofosbuvir in Tablets Formulation. J App Pharm Sci, 2017; 7 (02): 114-119. 